\title{
Thermophysical Properties of Cu-Matrix Composites Manufactured Using Cu Powder Coated with Graphene
}

\author{
T. Babul, M. Baranowski, N. Sobczak, M. Homa, and W. Leśniewski
}

\author{
(Submitted November 15, 2015; in revised form May 19, 2016; published online June 17, 2016)
}

\begin{abstract}
Compact $\mathrm{Cu}$ matrix composites reinforced with graphene were prepared by thermochemical processes and cold isostatic pressing. Thermophysical properties were investigated using laser flash analysis, differential scanning calorimetry, and dilatometry. From the results of the measurements, it follows that within the entire investigated temperature range, both the thermal diffusivity and the calculated values therefrom of the thermal conductivity of copper-graphene composites change according to the temperature changes. Above $500{ }^{\circ} \mathrm{C}$, abnormal decrease of the thermal diffusivity was registered for sample prepared from pure copper powder. In this case, the elevated temperature of test could cause sintering of copper particles, which were not coated by graphene. The as-received composites had higher thermal diffusivity and the thermal conductivity at the room temperature in comparison to the material obtained by standard pressing of pure copper powder. However, the production methods of some samples could cause their partial sintering. Based on the study, it could not be concluded that graphene only has impacts on the thermophysical properties.
\end{abstract}

Keywords cold isostatic pressing, graphene, metal-matrix composites, powder metallurgy

\section{Introduction}

The increasing demands for technical solutions enforce increased durability of products and improvement of their mechanical or physical properties. This makes the topic of modern materials as the subject of intense research in all the highly developed countries. One group of very popular materials, which appeared in numerous studies, is represented by carbon materials such as graphene $\left(\mathrm{C}_{\mathrm{Gn}}\right)$ or carbon nanotubes $(\mathrm{CNTs})$. In recent years, graphene has become a popular reinforcement material for metal matrix composites (Ref 1-7).

Graphene is two-dimensional, flat form of carbon, which has a single atom thickness and a hexagonal arrangement of atoms and possesses extraordinary mechanical, thermal, and electrical properties (Ref 8,9$)$. The combination of unique properties of graphene as a dispersed phase provides great potential to change properties of a new generation of advanced composite materials in aerospace or electronic fields (Ref 10).

Copper-graphene $\left(\mathrm{Cu}-\mathrm{C}_{\mathrm{Gn}}\right)$ composite is one of the scarcely studied metal matrix composites. However, driven by the Wan

This article is an invited submission to JMEP selected from presentations at the Symposium "Metal-Matrix Composites," belonging to the topic "Composite and Hybrid Materials" at the European Congress and Exhibition on Advanced Materials and Processes (EUROMAT 2015), held September 20 to 24, 2015, in Warsaw, Poland, and has been expanded from the original presentation.

T. Babul and M. Baranowski, Institute of Precision Mechanics, 3 Duchnicka St., 01-796 Warsaw, Poland; N. Sobczak, Foundry Research Institute, 73 Zakopianska St., 30-418 Krakow, Poland; and Motor Transport Institute, 80 Jagiellonska St., 03-301 Warsaw, Poland; and M. Homa and W. Leśniewski, Foundry Research Institute, 73 Zakopianska St., 30-418 Krakow, Poland. Contact e-mail: tomasz@imp.edu.pl. der Waals forces, graphene nanoplatelets are prone to agglomerate during the fabrication process. As agglomeration and structural destruction of carbon reinforcement often take place during ball-milling process or conventional powder metallurgy, some novel methods are developed for the manufacturing graphene on powders (Ref 11, 12).

The manufacturing of graphene on powders is a new approach in comparison to applying flat surfaces in previous, conventional methods. As a result, Graphene $3 \mathrm{D}^{\mathrm{IMP}}$ powder is obtained-a composite material, where graphene covers powders of $\mathrm{Cu}$. Graphene $3 \mathrm{D}^{\mathrm{IMP}}$ is produced by thermochemical processes. The method for producing Graphene $3 \mathrm{D}^{\mathrm{IMP}}$ is the combination of several processes, including CarboTermoFluid ${ }^{\circledR}$ technology and the technology described in the patent application P.409141 of 2014 (Ref 6, 10, 13).

The low cost of technological process opens up various possibilities for the use of Graphene $3 \mathrm{D}^{\mathrm{IMP}}$ for the production of a new generation of advanced materials. The technology enables coating of three-dimensional surface by graphene, which allows obtaining uniform materials - composites; $\mathrm{Cu}$ graphene coatings on substrates made of steel, light metals, and ceramics (Ref 7, 10).

Formation of elements from copper-graphene composite opens up a wide field for applications of this material, among others, in heat exchangers. For this reason, it is interesting to obtain information on the thermophysical properties (thermal diffusivity and thermal conductivity) of the $\mathrm{Cu}-\mathrm{C}_{\mathrm{Gn}}$ composite.

The paper presents the preliminary results of thermal conductivity studies conducted on $\mathrm{Cu}$-graphene composites fabricated from Graphene $3 \mathrm{D}^{\mathrm{IMP}}$.

\section{Experimental}

\subsection{Fabrication of Graphene $3 D^{I M P}$ and Bulk Cu-Graphene Composites}

Studies of the thermophysical properties were conducted on fabricated in the Institute of Precision Mechanics Warsaw $\mathrm{Cu}-$ 
graphene composites obtained by fluidization processes described elsewhere (Ref 13). Thermochemical processes were carried out on the stand for fluidization, which was produced by the Institute of Precision Mechanics. In the Graphene 3D ${ }^{\mathrm{IMP}}$ manufacturing, an analogy to the chemical vapor deposition (CVD) method was shown, where gases containing hydrocarbon also are the carbon source. CVD method allows coating large surfaces with graphene. However, in fluidization processes, it provides the movement of the small elements, the gas flows around each of them, and in this way, this method allows for the adsorption of graphene onto the base material in the powder form.

The procedure for the adsorption of graphene onto $\mathrm{Cu}$ powders included the following steps: (1) fluidization under gases containing hydrocarbons in working chamber (the process is assisted by the introduction of vibrations); (2) high-temperature decomposition of hydrocarbons which act as the carbon source in the production of Graphene $3 \mathrm{D}^{\mathrm{IMP}}$; (3) nucleation and growth of carbon structures on the surface of the $\mathrm{Cu}$ (which occurs through interaction of gases containing hydrocarbon, surrounding the particles of powder) (Ref 13).

$\mathrm{Cu}$-graphene specimens (disks) were obtained by isostatic pressing at the Institute of High Pressure Physics of the Polish Academy of Sciences. For the preparation of $\mathrm{Cu}$-graphene specimens, the different proportions of the $\mathrm{Cu}$ powders, Graphene $3 \mathrm{D}^{\mathrm{IMP}}$ powders and their mixtures were used (Table 1). The pressures of isostatic pressing were set minimum to ensure the consolidation of the samples. For 100 wt.\% $\mathrm{Cu}$ powders, it was $200 \mathrm{MPa}$; for other variants, it was $1 \mathrm{GPa}$. In addition, samples $2,4,5$, and 6 were coated by graphene at a temperature of $1000^{\circ} \mathrm{C}$ after pressing. Characteristics of powders and processes for the production of $\mathrm{Cu}$-graphene specimens are compiled in Table 1.

Structural characterization and thermophysical properties were performed using the following techniques:

1. Raman spectroscopy using Jobin-Yvon-Spex T64000 Raman spectrometer

2. Scanning electron microscopy (SEM) using LEO 435VP device equipped with energy-dispersive $\mathrm{X}$-ray spectroscopy (EDS) analyzer and TM3000 HITACHI.

3. Differential scanning calorimetry (DSC) that measures the specific heat on a Netzsch DSC $404 \mathrm{C} / 3 / \mathrm{G}$ Pegasus scanning calorimeter. Tests were performed in a protective atmosphere of $\mathrm{Ar}$ in the temperature range from 25 to $1050{ }^{\circ} \mathrm{C}$ with the heating rates of 5 and $20 \mathrm{~K} / \mathrm{min}$.

Dilatometry (DIL) is used to investigate changes in thermal expansion using a high-temperature Netzsch DIL 402C/4/G dilatometer. Tests were performed in a protective atmosphere of $\mathrm{Ar}$ in the temperature range from 25 to $900{ }^{\circ} \mathrm{C}$ under the lowrate heating conditions $(5 \mathrm{~K} / \mathrm{min})$.

To characterize the thermal diffusivity and thermal conductivity, the laser flash analysis (LFA) measurement technique was used using a Netzsch LFA 427 apparatus set. The studies were conducted in vacuum of $10^{-4} \mathrm{mbar}$ in the temperature range from 25 to $900{ }^{\circ} \mathrm{C}$. The $\lambda(T)$ values were calculated taking into consideration the radiation losses, based on the nonlinear regression and Cape-Lehman model.

\section{Results}

The conducted microscopic observations confirmed the manufacturer's data on powder $\mathrm{Cu}$ characteristics, including type and grain size (Fig. 1).

Manufacturing of graphene on the $\mathrm{Cu}$ grains at high temperature leads to the initial sintering of the output material (joints formed between the particles) (Fig. 2a) and the loss of dendritic structure (Fig. 2b).

In order to evaluate technological processes, Graphene 3D ${ }^{\mathrm{IMP}}$ powders were tested using a Raman spectrometer (Fig. 3).

Exemplary Raman spectra revealed that 2D, G, and D peaks are clearly visible on the spectra. 2D and G peaks are typical for the Raman spectrum of graphene, confirming its presence on the tested powders. D peak indicates the possibility of the presence of graphene oxide.

$\mathrm{Cu}$-graphene specimens in the form of disk were obtained by isostatic pressing (Fig. 4). The specimens of $\mathrm{Cu}$-graphene were used for the preparation of metallographic polished sections and examination of their microstructures. In this article, images were not shown, but the results of the microstructure examinations of all the specimens indicate that

Table 1 Proportions of $\mathrm{Cu}$ powders, graphene-coated $\mathrm{Cu}$ powders and their mixtures used for isostatic pressing

\begin{tabular}{|c|c|c|c|c|}
\hline \multirow[b]{2}{*}{ No. } & \multirow[b]{2}{*}{ Type of Cu powder } & \multicolumn{2}{|c|}{ Powders proportions in wt.\% } & \multirow[b]{2}{*}{ Processes in chronological order } \\
\hline & & $\mathbf{C u}$ & Cu powder covered by graphene & \\
\hline 1 & Dendritic & 100 & & Pressing the $\mathrm{Cu}$ powder \\
\hline 2 & Dendritic & 100 & & $\begin{array}{l}\text { Pressing the } \mathrm{Cu} \text { powder } \\
\text { Coating the sample with graphene } \\
\text { after pressing } \\
\text { Re-pressing the sample }\end{array}$ \\
\hline 3 & Spherical & 90 & 10 & Pressing the mixture of powders \\
\hline 4 & Spherical & 90 & 10 & $\begin{array}{l}\text { Pressing the mixture of powders } \\
\text { Coating the sample with graphene } \\
\text { after pressing }\end{array}$ \\
\hline 5 & Spherical & 80 & 20 & $\begin{array}{l}\text { Pressing the mixture of powders } \\
\text { Coating the sample with graphene } \\
\text { after pressing }\end{array}$ \\
\hline 6 & Spherical & & 100 & $\begin{array}{l}\text { Pressing the } \mathrm{Cu} \text { powder } \\
\text { Coating the sample with graphene } \\
\text { after pressing }\end{array}$ \\
\hline
\end{tabular}




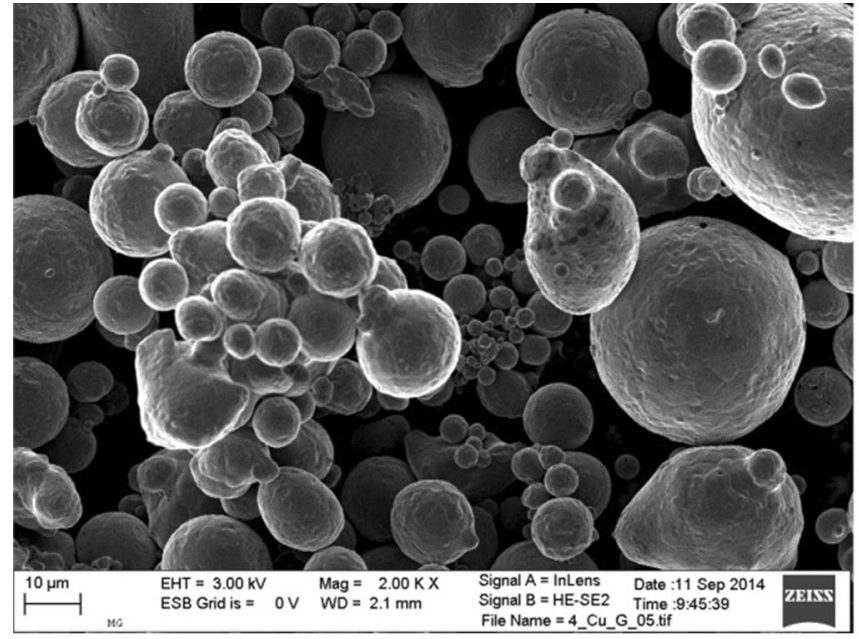

(a)

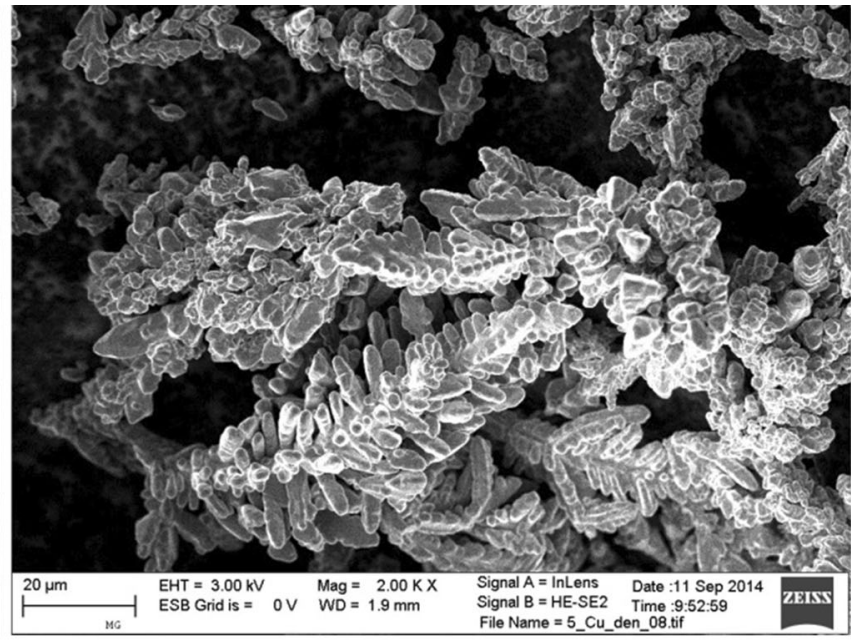

(b)

Fig. 1 SEM images of base components used in the fabrication of Graphene $3 \mathrm{D}^{\mathrm{IMP}}$ : spherical $\mathrm{Cu}$ powder (a) and dendritic $\mathrm{Cu}$ powder (b)

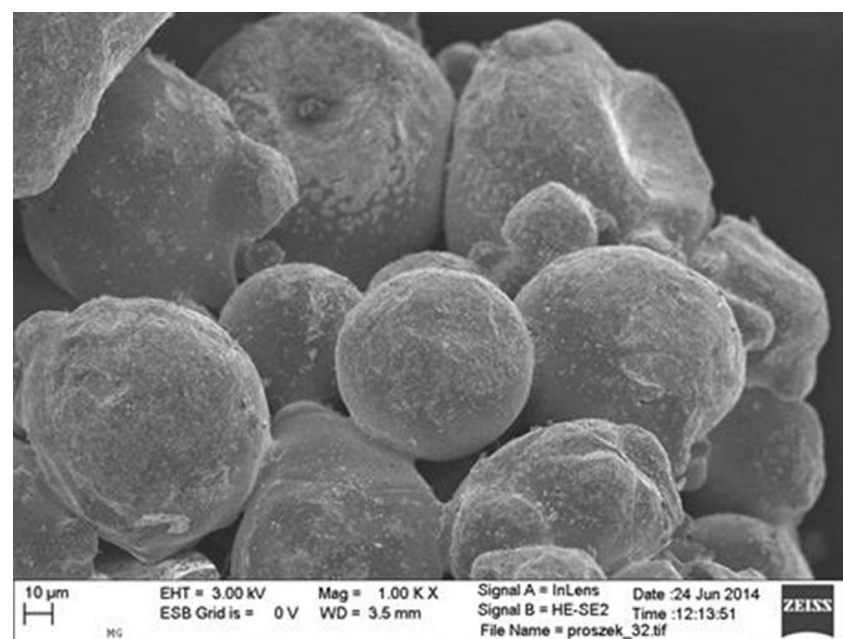

(a)

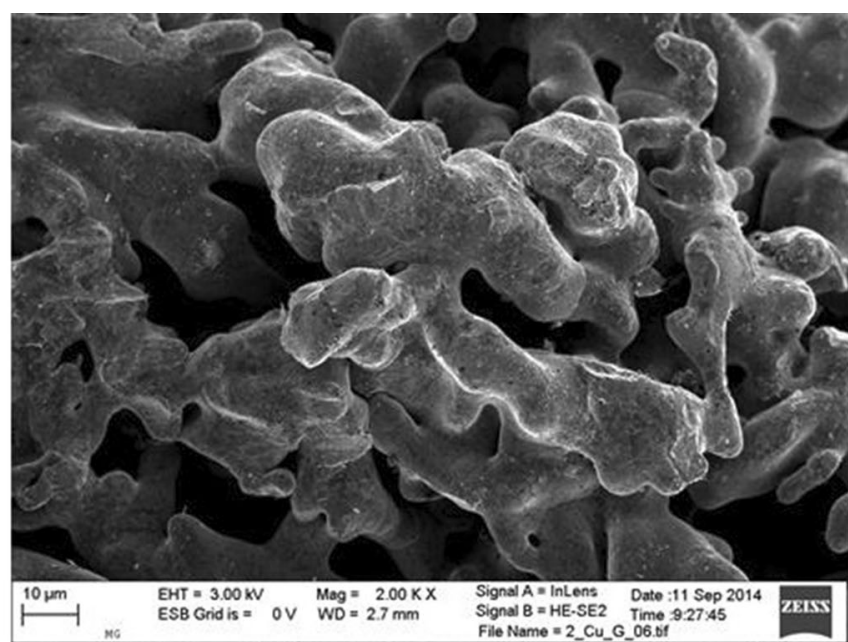

(b)

Fig. 2 SEM images of $\mathrm{Cu}$ powder particles after graphene coating: spherical $\mathrm{Cu}$ powder (a) and dendritic $\mathrm{Cu}$ powder (b)
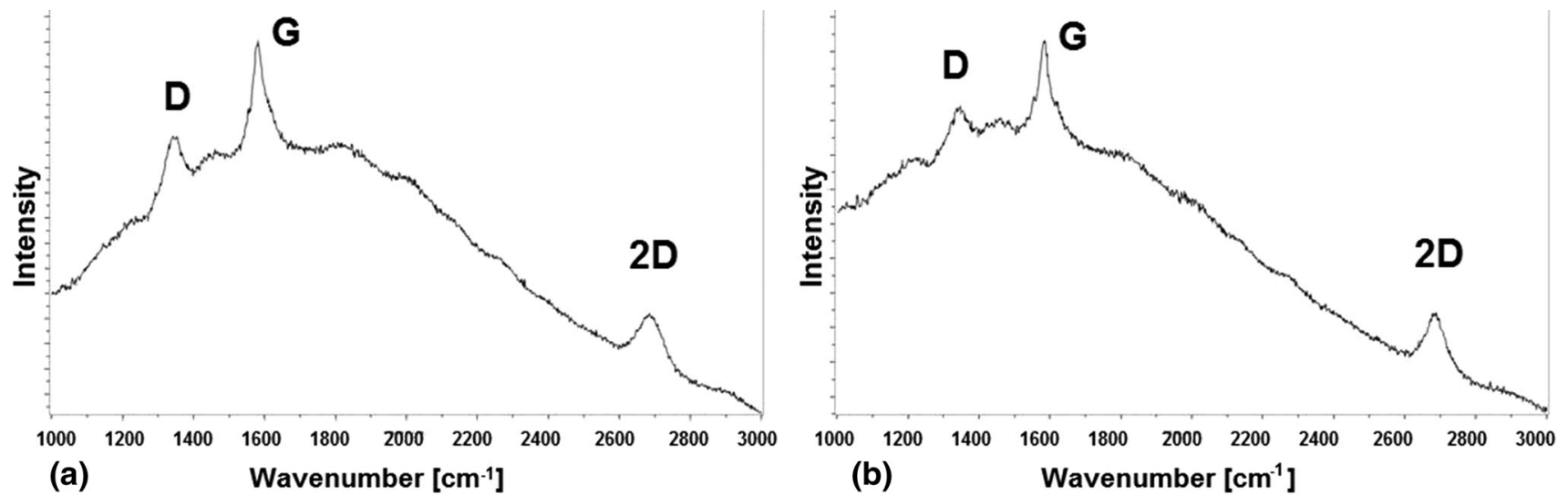

Fig. 3 Raman spectra of graphene deposited on $\mathrm{Cu}$ powders with different morphologies: (a) spherical and (b) dendritic 


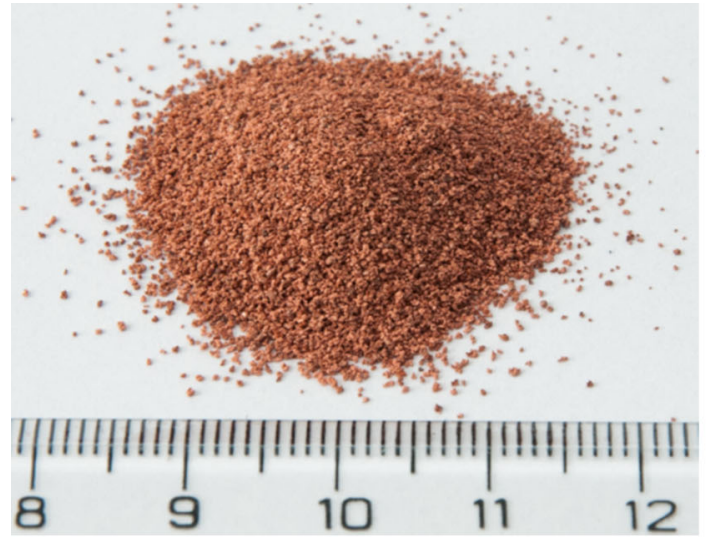

(a)

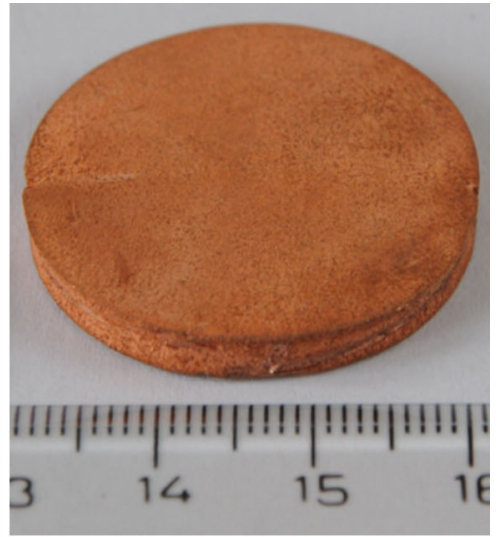

(b)

Fig. 4 Photos (a) of dendritic $\mathrm{Cu}$ powder covered by graphene and (b) of example Cu-graphene specimen (disk) after cold isostatic pressing

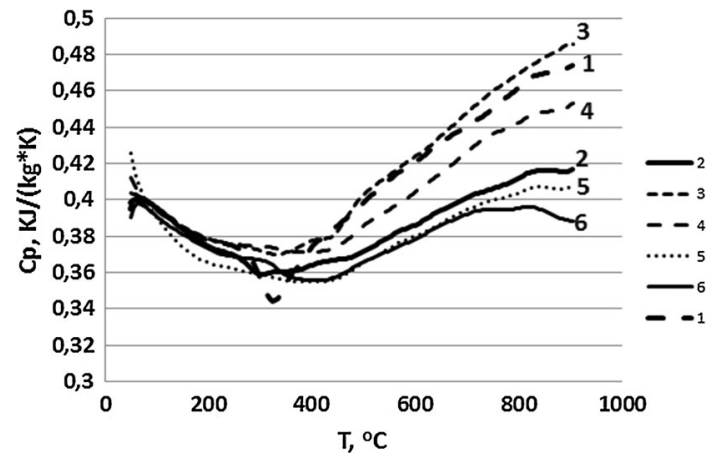

Fig. 5 DSC exemplary measuring curves of $\mathrm{Cu}-\mathrm{C}$ composites

their structure is homogeneous at high magnifications up to $\times 5000$.

Disks, received by cold isostatic pressing, were characterized by a compact structure. During the machining (cutting test samples) samples 3 and 5 showed significant embrittlement.

Calorimetric measurements showed similar $C_{\mathrm{p}}$ curves of tested materials (Fig. 5). No energetic effects were observed in the tested temperature range. In the case of the sample made of $100 \% \mathrm{Cu}$ at temperature $300{ }^{\circ} \mathrm{C}$, an exothermic thermal effect is visible.

For $\mathrm{Cu}-\mathrm{C}$ composites, the analysis of the relative elongation as a function of temperature showed approximately linear nature of the function (Fig. 6). The increase of the temperature caused an increase of the relative elongation. At temperature $300{ }^{\circ} \mathrm{C}$, pure copper powder sample shows a sharp increase in elongation. Dilatometric curves showed no significant differences between the various contents of $\mathrm{Cu}$ powder coated by graphene.

The as-received dilatometric curves allowed us to calculate the average values of the thermal expansion coefficient $\alpha$ (Fig. 7). For the calculation, the test results obtained during the heating of samples from 25 to $900{ }^{\circ} \mathrm{C}$ were used. The changes in the value of the thermal expansion coefficient $\alpha$ are shown in Fig. 7.

In temperature relations of the thermal expansion coefficient $\alpha$, two stages can be noticed. In the range of 25 to $100{ }^{\circ} \mathrm{C}$, slow increase in the values of the thermal expansion coefficients $\alpha$

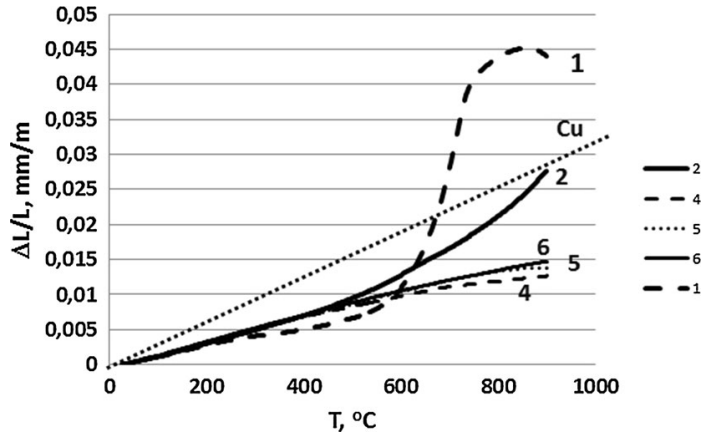

Fig. 6 Linear expansion curves of $\mathrm{Cu}-\mathrm{C}$ composites

occurred. However, in the range of 100 to $900{ }^{\circ} \mathrm{C}$, the values of the thermal expansion coefficients $\alpha$ stabilize and depend on temperature slightly.

Temperature-related changes in the coefficients of thermal diffusivity $(a)$ and thermal conductivity $(\lambda)$ are presented in Fig. 8 and 9.

Based on the performed measurements, it was ascertained that in the entire temperature range for tested materials, the thermal diffusivity changes with temperature (Fig. 8). For samples 2, 4, 5, and 6, temperature rise causes a decrease in thermal diffusivity. In the temperature range from 25 to $900{ }^{\circ} \mathrm{C}$ for the sample 2, the difference was about $50 \mathrm{~mm}^{2} / \mathrm{s}$; for the samples 4,5 , and 6 , the differences were lower $\left(7-16 \mathrm{~mm}^{2} / \mathrm{s}\right)$. Thermal diffusivity of the sample 1 was increasing in the temperature range of $200-400{ }^{\circ} \mathrm{C}$, and then began to decrease. This rise caused that, in the temperature range of $300-600{ }^{\circ} \mathrm{C}$, the thermal diffusivity of $\mathrm{Cu}$ (sample 1) was higher than the thermal diffusivities of the samples 4,5 , and 6 . The increase and the decrease of thermal diffusivity registered for the sample 3 were similar to those for the sample 1 .

At room temperature, the lowest values of thermal diffusivity were registered for the samples 1 and 3. Thermal diffusivity values doubled for the samples 4, 5, and 6, and more than thrice for the sample 2. Considerably smaller differences were registered at $900{ }^{\circ} \mathrm{C}$, but still the highest value was registered by the sample 2 . The lowest thermal diffusivity was obtained for the reference sample 1 .

Similar to the thermal diffusivity, the thermal conductivity changes with temperature. For the sample 2, the temperature 


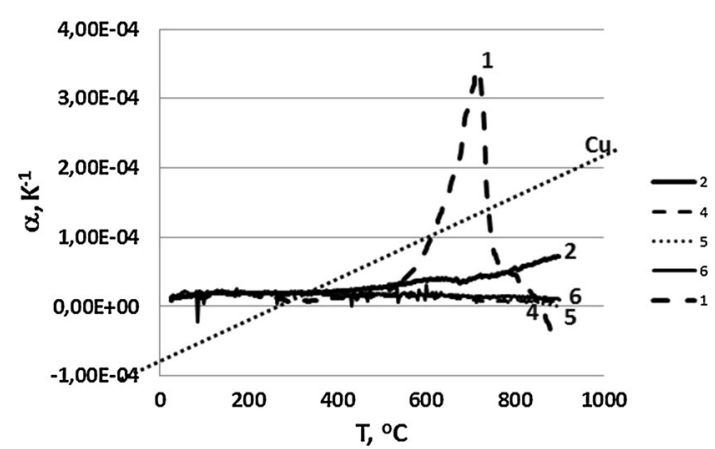

Fig. 7 CTE exemplary measuring curves of $\mathrm{Cu}-\mathrm{C}$ composites

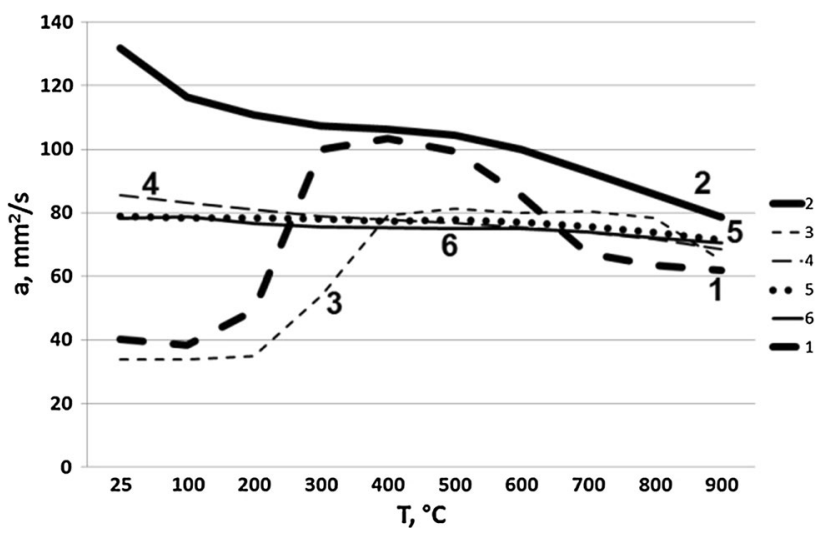

Fig. 8 Curves interrelating temperature with thermal diffusivity $\mathrm{a}(T)$

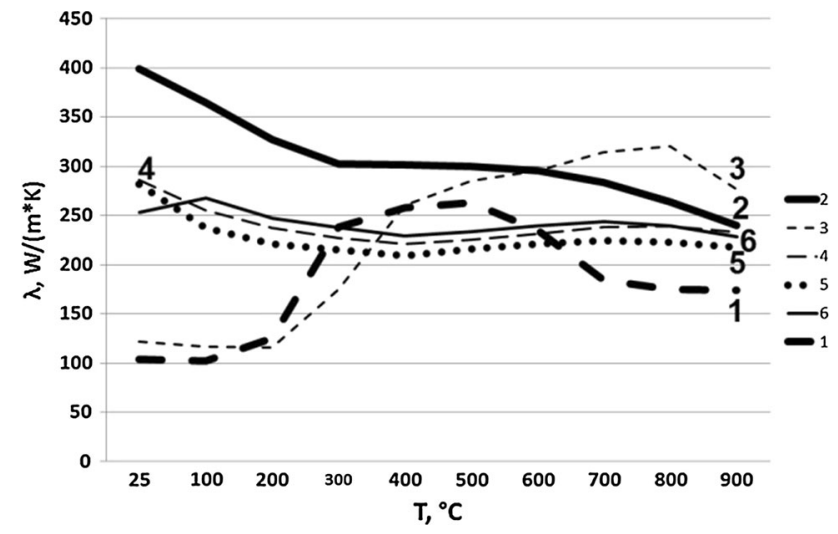

Fig. 9 Curves interrelating temperature with thermal conductivity $\lambda(T)$

rise caused a decrease of thermal conductivity. In the temperature range of $25-900{ }^{\circ} \mathrm{C}$, the thermal conductivity values of the samples 4, 5, and 6 were at a steady level. Thermal conductivity of the sample 1 started to increase first in the temperature range of $200-500{ }^{\circ} \mathrm{C}$, and then began to decrease. In the temperature range of $400-500{ }^{\circ} \mathrm{C}$, the thermal conductivity of $\mathrm{Cu}$ (sample 1) was higher than the thermal conductivity values of the samples 4,5 , and 6 . Values of thermal conductivity of the sample 3 were changing similar to that for the sample 1 .

At room temperature, the lowest values of thermal conductivity were registered for the samples $1(104 \mathrm{~W} / \mathrm{m} \mathrm{K})$ and 3 $(121 \mathrm{~W} / \mathrm{m} \mathrm{K})$. Thermal conductivity values for samples 4, 5, and 6 were higher by more than $130 \mathrm{~W} / \mathrm{m} \mathrm{K}$, and, for the sample 2 , higher by more than $270 \mathrm{~W} / \mathrm{m} \mathrm{K}$. At $900{ }^{\circ} \mathrm{C}$, the lowest values of thermal conductivity were registered for the sample 1, but the highest thermal conductivity was obtained for the sample 3 .

\section{Discussion}

Manufacturing of composites of $\mathrm{Cu}$-graphene under the conventional method of powder metallurgy brings many problems. Just ball-milling process can lead to the destruction of the carbon structures. The agglomeration of graphene, driven by the van der Waals forces, is another problem. There are also difficulties associated with poor affinity and a large thermal expansion mismatch between $\mathrm{Cu}-\mathrm{C}$. These factors can reduce performance of the composites later in operation (Ref 11, 12, 14).

The use of copper powders coated with graphene, for the manufacturing of compact composite materials, eliminates the problem of agglomeration of the carbon phase. Graphene $3 \mathrm{D}^{\mathrm{IMP}}$ manufacturing also causes a partial sintering of material (compaction). Most of the resulting compact composites of $\mathrm{Cu}-$ graphene composites in the form of disks have a good mechanical strength. Such behaviors may be related to the presence of graphene oxide, as a source of oxygen, which can influence the formation of $\mathrm{Cu}-\mathrm{O}$ bonds on the surface of the powder copper.

The presence of graphene in the $\mathrm{Cu}$-matrix materials generates a high dislocation density in its vicinity. The result is an increase in yield strength, but the fragility of the material increases as well (Ref 11, 15). This was confirmed during machining attempts of samples 3 and 5, which were characterized by considerable fragility.

In many attempts of $\mathrm{Cu}-\mathrm{C}$ composites manufacturing, the obtained material had worse thermal properties compared to pure copper. This might be caused by agglomeration of graphene or by the formation of voids due to the thermal expansion mismatch of the $\mathrm{Cu}-\mathrm{C}(\operatorname{Ref} 11,16)$.

Using $\mathrm{Cu}$ powder covered with graphene as a starting material for the production of a uniform material ensures no agglomeration of the filler. In Raman spectroscopy, the D peak indicates the disorder of carbon material and the possibility of the presence of graphene oxide. As a result, $\mathrm{Cu}-\mathrm{O}$ bonding can form at the interface of copper matrix composites (Ref 17, 18), which is beneficial to join matrix and filler. In case of samples 2, 4, 5, and 6, the coating of the pressed $\mathrm{Cu}$ powders with graphene was applied, so that carbon could penetrate voids in the pressed material. Applying high temperature during coating of the pressed samples with graphene could cause sintering of the particles. For the composites obtained in this way, at room temperature, the thermal diffusivity and the thermal conductivity increased in comparison to the pressed copper powder. 
For samples 2, 4, 5, and 6 thermal diffusivities and the thermal conductivities decreased with the increasing temperature. A factor, which affects the results is thermal expansion mismatch of $\mathrm{Cu}-\mathrm{C}$. The rise of temperature causes size increase of voids, which form insulating barrier to the heat flow.

Curves interrelating temperature with thermal conductivity $\lambda(T)$ for samples $2,4,5$, and 6 have a different behavioral nature from the ones for the samples 1 and 3 . It could be caused by the possibility of sintering samples during coating of the sample with graphene after pressing. Above $500{ }^{\circ} \mathrm{C}$, abnormal decrease of the thermal diffusivity was registered for sample 1 - pure copper. In this case, the elevated temperature of test could cause sintering of copper particles which were not coated by graphene.

The way of sample preparation does not allow us to reliably determine the impact of graphene on thermophysical properties. Significant in this case is also the possibility of the particles sintering during the sample preparation.

Solid copper has higher thermal conductivity than these composites, but in this paper only materials manufactured from the powder were tested.

\section{Conclusions}

The paper presents the results of trials to fabricate $\mathrm{Cu}$ graphene composites. Measurements of thermophysical properties of the produced materials were shown.

The Institute of Precision Mechanics developed a low-cost manufacturing technology of the modern material which is Graphene 3D ${ }^{\mathrm{IMP}}$.

Methods of producing solid material from the graphenecoated $\mathrm{Cu}$ powder were elaborately discussed.

At room temperature, the as-received composites had higher thermal diffusivity and the thermal conductivity in comparison to the standard pressed copper powder.

\section{Acknowledgments}

Graphene $3 \mathrm{D}^{\mathrm{IMP}}$ was obtained in the project. The study of technological and material parameters, affecting the stability of the manufacturing process of 3d-type graphene on copper powders." The studies have been carried out under the Project No. 5628/00 entitled "Effect of the HIP on the thermal properties of composites made from graphene 3DIMP-coated copper powders produced by ThermoCarboFluid $^{\circledR}$ method." The dilatometric and thermogravimetric measurements were performed on an apparatus purchased under the Structural Project No. POIG.02.02.00-00-012/08 entitled: "Retrofitting the research infrastructure of Małopolska Center for Innovative Technologies and Materials." To perform thermal diffusivity and thermal conductivity studies, an LFA 427 apparatus purchased by Foundry Research Institute (Decision No. 425/E-141/ S/2007-2) was used.

\section{Open Access}

This article is distributed under the terms of the Creative Commons Attribution 4.0 International License (http://creativecommons.org/ licenses/by/4.0/), which permits unrestricted use, distribution, and reproduction in any medium, provided you give appropriate credit to the original author(s) and the source, provide a link to the Creative Commons license, and indicate if changes were made.

\section{References}

1. P.H.G. Kumar and M.A. Xavior, Graphene Reinforced Metal Matrix Composite (GRMMC) a Review, Proc. Eng., 2014, 97, p 1033-1040

2. P.G. Slade, Electrical Contacts Principles and Applications, Marcel Dekker, New York, 1999

3. Y. Feng, H.L. Yuan, and M. Zhang, Fabrication and Properties of Silver-Matrix Composites Reinforced by Carbon Nanotubes, Mater. Charact., 2005, 55, p 211-218

4. K. Jagaannadham, Thermal Conductivity of Copper-Graphene Composite Films Synthesized by Electrochemical Deposition with Exfoliated Graphene Platelets, Metall. Mater. Trans. B, 2012, 43B, p 316-324

5. E.Y. Nzoma, A. Gulliet, and P. Pareige, Nanostructured Multifilamentary Carbon-Copper Composites: Fabrication, Microstructural Characterization and Properties, J. Nanomater. 2012. doi:10.1155/2012/360818

6. M. Trzaska, T. Babul, Z. Obuchowicz, and G. Cieślak, Production of Graphene and Nanocomposites of Metal/Graphene, Conference Nano PL 2014 "Nanotechnology and Advanced Materials for Innovative Industry”, Kielce INNO TECH EXPO 2014, 15-17.10.2014, Book of Abstracts, p 27-28

7. M. Trzaska, G. Cieślak, and Z. Powłoki, Nowych Nanokompozytowych Materiałów Nikiel/Grafen o Korzystnych Właściwościach Eksploatacyjnych. In: 8th International Warsaw Invention Show IWIS 2014, Warsaw, 14-16 October 2014, Book of Abstracts, p 64 (in polish)

8. A.K. Geim and K.S. Novoselov, The Rise of Graphene, Nat. Mater, 2007, 6, p 183-191

9. A.K. Geim, Graphene: Status and Prospects, Science, 2009, 324, p $1530-1534$

10. T. Babul, M. Trzaska, J. Jeleńkowski, and A. Wojciechowski, Potencjał Grafenu 3DIMP, Logistyka, 2015, 4, p 2282-2291 (in polish)

11. F. Chen, J. Ying, Y. Wang, S. Du, Z. Liu, and Q. Huang, Effects of Graphene Content on the Microstructure and Properties of Copper Matrix Composites, Carbon, 2016, 96, p 836-842

12. N. Darsono, D.-H. Yoon, and J. Kim, Milling and Dispersion of Multiwalled Carbon Nanotubes in Texanol, Appl. Surf. Sci., 2008, 54(11), p 3412-3419

13. Z. Obuchowicz, M. Baranowski, T. Babul, and N. Sobczak, Kompozyty Cu-Grafen 3DIMP, Inż. Powierz., 2015, 20(2), p 10-14 (in polish)

14. K. Morsi and A. Esawi, Effect of Mechanical Alloying Time and Carbon Nanotube (CNT) Content on the Evolution of Aluminum (Al)eCNT Composite Powders, J. Mater. Sci., 2007, 42(13), p 4954-4959

15. J.N. Wei, Z.B. Li, and F.S. Han, Thermal Mismatch Dislocations in Macroscopic Graphite Particle-reinforced Metal Matrix Composites Studied by Internal Friction, Phys. Status Solidi A, 2002, 191(1), p 125-136

16. C.W. Nan, R. Birringer, D.R. Clarke, and H. Gleiter, Effective Thermal Conductivity of Particulate Composites with Interfacial Thermal Resistance, J. Appl. Phys., 1997, 81(10), p 6692-6699

17. J. Hwang, T. Yoon, S.H. Jin, J. Lee, T.-S. Kim, S.H. Hong et al., Enhanced Mechanical Properties of Graphene/Copper Nanocomposites Using a Molecularlevel Mixing Process, Adv. Mater, 2013, 25(46), p 6724-6729

18. K.T. Kim, S. Cha, T. Gemming, J. Eckert, and S.H. Hong, The Role of Interfacial Oxygen Atoms in the Enhanced Mechanical Properties of Carbon-Nanotubereinforced Metal Matrix Nanocomposites, Small, 2008, 4(11), p 1936-1940 